\title{
Comparison of Connective Tissue Graft and Platelet Rich Fibrin as Matrices in A Novel Papillary Augmentation Access: A Randomized Controlled Clinical Trial
}

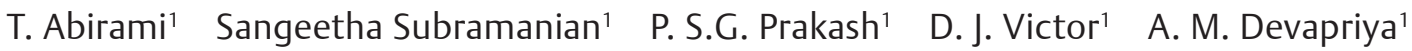 \\ 1SRM Dental College and Hospital, Ramapuram, Chennai, \\ Tamil Nadu, India \\ Address for correspondence T. Abirami, MDS, Post Graduate, \\ 4/222, MIG, Twin House, Mogappair West, Chennai 600037, \\ Tamil Nadu, India (e-mail: abitm.ds@gmail.com).
}

Eur J Dent 2019;13:607-612

\begin{abstract}
Objective The present study was a randomized controlled clinical trial with the aim of evaluating the increase in papillary height and reduction in black triangle height obtained by the novel papillary augmentation access with either connective tissue graft (CTG) or platelet-rich fibrin (PRF) as matrix from baseline to 6 months.

Materials and Methods A total number of 20 sites with Nordland and Tarnow's Class I, I-II and II interdental papillary loss were recruited into the study. The sites were randomly allocated with 10 sites per group into either: Group A (control group) or Group $B$ (test group) which utilizes the same technique with CTG or PRF as matrix, respectively. The clinical parameters such as PPD (probing pocket depth) and CAL (clinical attachment level) at the surgical site, plaque score (FMPS), bleeding scores (FMBS), interdental papillary height (PH) and black triangle height (BTH), along with visual analog score by dentist (VAS-D) and by patient (VAS-P) were evaluated at baseline and at 6 months.

Results In both CTG and PRF groups, all the primary and secondary outcome variables such as PH, BTH, VAS-D and VAS-P showed statistically significant improvement from baseline to 6 months $(p \leq 0.05)$ within the group. On comparison at 6 months,

Keywords

- black triangle

- connective tissue graft

- interdental papilla

- papillary loss

- papilla reconstruction

- platelet rich fibrin there were no differences in the papillary height between the groups. However, the BTH has significantly reduced in the CTG group than the PRF group. Similarly, the VAS-D significantly improved in the CTG group than the PRF group $(p=0.010)$ at 6 months.

Conclusion The study demonstrates that the proposed papillary augmentation access with CTG and PRF was successful in managing the unaesthetic interdental papillary loss, with CTG showing better results in terms of reduction of black triangle than PRF.
\end{abstract}

\section{Introduction}

The absence of interdental papilla is known as "Angulus Nigrens" or black triangles in common terminology. Black triangles are nothing but the open embrasure spaces which are devoid of the interdental papilla. They are present in more than one third of all adults and are more frequent in patients who suffer bone loss. ${ }^{1}$ Various etiologic factors for interdental papillary loss are ${ }^{2}$ microbial tooth deposit-associated periodontal disease, tooth contour and form, absence of adjacent teeth, inadvertent usage 
of oral hygiene maintenance devices, interdental spacing, and improper contour of the restoration or denture.

When the periodontal management of papillary loss is reviewed, there are multiple techniques that have been described previously in the literature. Beagle et al in $1992^{3}$ performed a partial thickness flap which was suspended and secured coronally, so as to fill the papillary space. Han and Takei in $1996^{4}$ also described a technique with semilunar incision and coronal advancement of the papillary unit, where they reported an optimal augmentation of the papilla. However, majority of the techniques were flap elevation-based procedures. Considering the importance of vascularity, tunneling-based augmentation procedures have been introduced, without having to incise the interdental papilla, which aids in accelerated wound healing. Even in these procedures, the tunnel was prepared either on the buccal ${ }^{5-7}$ or the palatal aspect. ${ }^{8}$

On further reviewing the literature, few other authors improvised the papillary augmentation technique with the incorporation of biological matrices, so as to counter the dead space. In the initial era of soft tissue regeneration, connective tissue graft (CTG) was proven to be a gold standard matrix for augmentation of papilla. ${ }^{8,9}$ Later, autologous, bioactive platelet-rich fibrin (PRF) has been shown to have a potential to serve as an autologous matrix that promotes differentiation of progenitor cells into the matrix, thereby potentiating regeneration. ${ }^{10-14}$

Majority of the literature published were only case reports/case series and there were only limited clinical trials published for papillary augmentation ${ }^{15,16}$ Taking all these factors into consideration, the current study proposes a minimal accessed labial and palatal tunneling across the interdental gingiva to facilitate the placement of a CTF/PRF, so as to augment the papillary height. The study was designed as a randomized controlled clinical trial, with the aim of comparing the role of two different autologous matrices-CTG/PRF-to augment the papilla dimensions and reduce the black triangle height at 6 months.

\section{Materials and Methods}

Sample size calculations were done based on an article published by Shruthi et al in 2016, ${ }^{15}$ which is the only closely relevant article to the present study. Based on their results and applying 5\% $\alpha$ error and $80 \%$ power, the sample size required was 20 sites with 10 sites in each group. The study groups for the present study are as follows: Group A (Control group-CTG) and Group B (Test group-PRF) with 10 sites per group. The ethical approval number of the present study is SRMDC/IRB/2016/MDS/No.501.

A. Inclusion Criteria: a. Class I, II and I-II interdental papillary loss based on Nordland and Tarnow's classification; b. Recession less than $2 \mathrm{~mm}$ on the facial or lingual aspect; c. No active periodontal disease; $\boldsymbol{d}$. Patients with adequate width of attached gingiva; e. No systemic conditions or medication known to interfere with periodontal tissue health or healing; f. Not more than one site per quadrant was taken in the maxillary anterior esthetic region
B. Exclusion Criteria: a. Previous periodontal surgery within six months; b. Pregnant/lactating women; c. Usage of tobacco/tobacco products in past 6 months; d. Patients unwilling for the surgery; e. Patients with inadequate plaque control; f. Edentulous site adjacent to the site of surgery; g. Platelet count less than one lakh cells per cubic $\mathrm{mm}$. Patients who satisfied the selection criteria and belonged to Nordland and Tarnow class I and II were selected for the study. Patients who demonstrated adequate standard of oral hygiene, that is, full mouth plaque scores (FMPS) and bleeding scores (FMBS) less than or equal to $20 \%$ were taken for surgery. A single calibrated examiner who is blinded to the patient allocation into groups measured all the clinical parameters at baseline and 6 months postoperatively.

The following clinical parameters were evaluated in all the recruited patients:

1. FMPS (O'leary index in 1972) ${ }^{17}$

2. FMBS (Ainamo and Bay in 1975) $)^{18}$

3. Mean-probing pocket depth (PPD)

4. Mean-clinical attachment level (CAL)

5. Site-specific-PPD

6. Site-specific-CAL

Points 5 and 6 are four proximal sites which are present adjacent to the concerned interdental papilla

7. Height of the black triangle (BTH)-measured from tip of the papilla to the apical most point of the interdental contact area

8. Interdental papillary height (PH)-measured from line connecting zenith of the two adjacent teeth and tip of the papilla

Mean PPD, Mean CAL, and Nordland and Tarnow classification were evaluated at baseline for the recruitment of samples, whereas other parameters were evaluated at both baseline and six months. Additionally, VAS by patients and dentists were evaluated based on a scale of 10 at the end of six months. The preoperative and postoperative photographs of each patient were placed in a single slide of the power point presentation in an equal aspect ratio. The patients were then asked to score their preoperative and postoperative photographs for esthetics on the basis of the above given scale. Similarly, three periodontists were asked to score all the preoperative and postoperative photographs for the papillary fill independently based on the above-mentioned scale. All of them were blinded to the surgical treatment performed. The average of all the three scores were taken for statistical analysis.

The recruited sites for the study were randomized based on their enrolment number. A single experienced operator performed all the surgical procedures.

\section{Surgical Procedure}

Following local anesthesia, a full thickness horizontal incision was given at the level of mucogingival junction in the buccal aspect and at the level of 2 to $3 \mathrm{~mm}$ above the base 


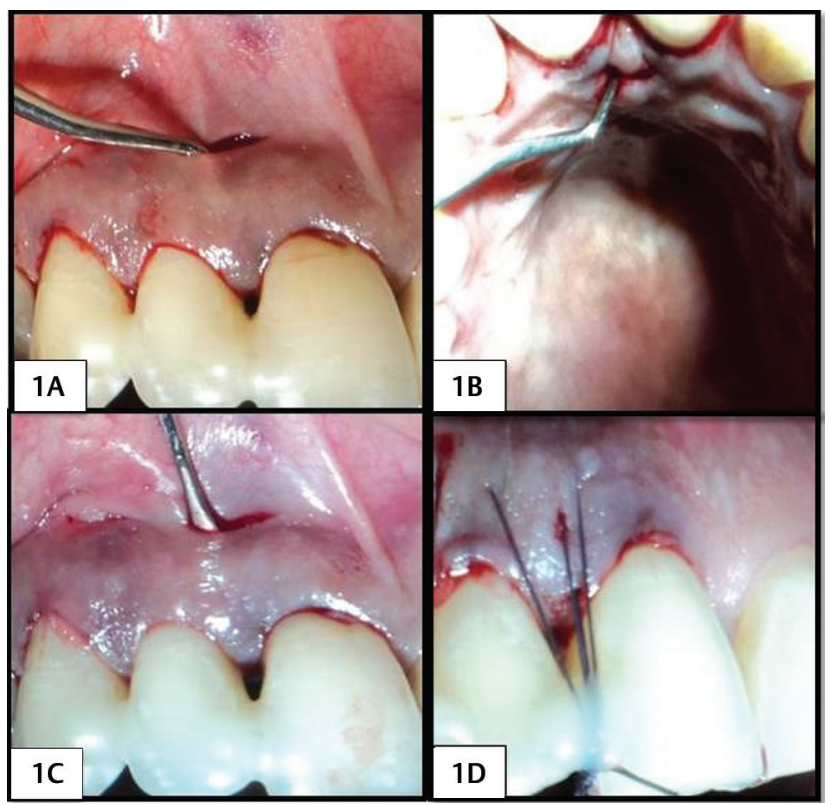

Fig. 1 (1A) Buccal horizontal incision and tunneling in PRF group. (1B) Palatal horizontal incision and tunneling in PRF group. (1C) Placement of the PRF. (1D) Horizontal and vertical mattress suture placement with composite stops in PRF group.

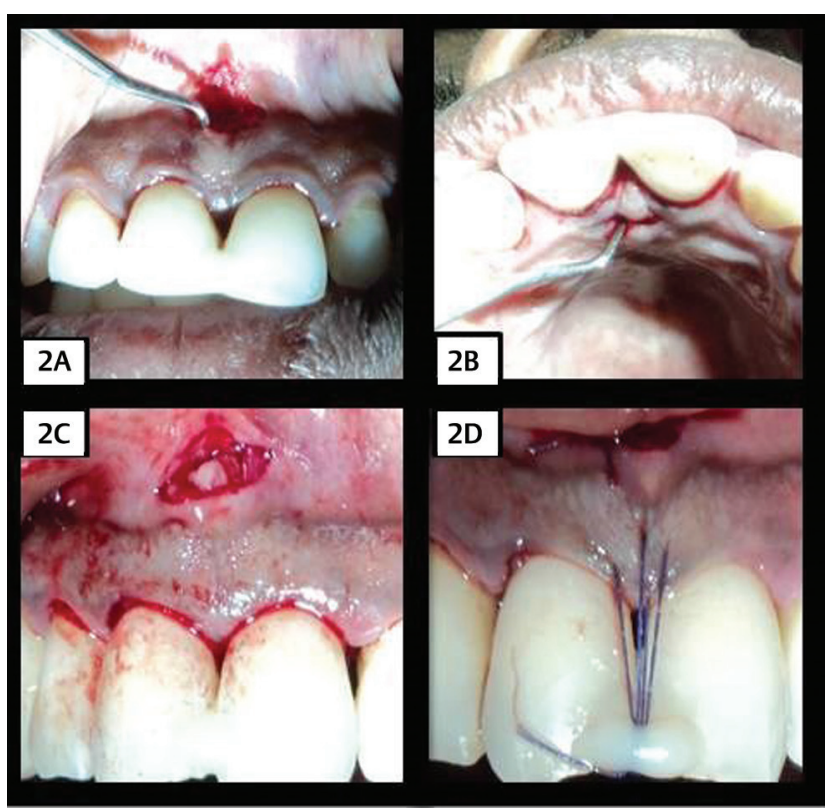

Fig. 2 (2A) Buccal horizontal incision and tunneling in CTG group (2B) Palatal horizontal incision and tunneling in CTG group (2C) Placement of the CTC (2D) Horizontal and vertical mattress suture placement with composite stops in CTG group.

of the papilla in the palatal aspect, which was not more than 2 to $3 \mathrm{~mm}$ wide. A crevicular incision was given along the buccal and palatal region of the adjacent teeth without splitting the interdental gingiva. Tunnels were prepared on the buccal and palatal aspect, extending from the horizontal incision to the interdental area using tunneling knives (-Fig. 1A, 1B and 2A, 2B). For the control group, CTG was placed as the matrix, whereas for test group, PRF was placed as the matrix ( - Fig. 1C, $\mathbf{2 C}$ ). CTG was harvested from the palate by a single incision technique with a

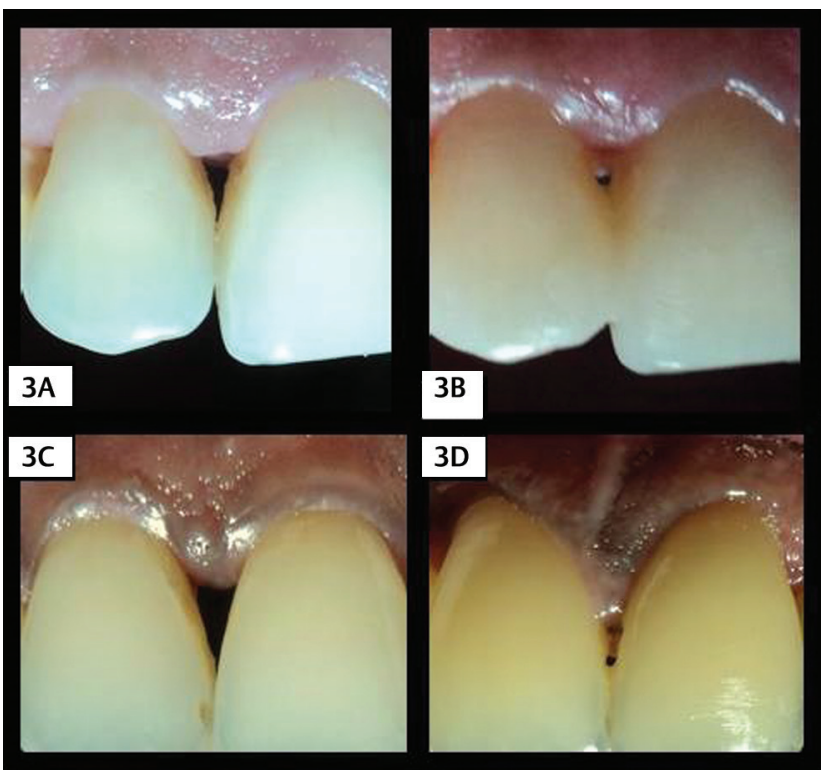

Fig. 3 (3A) Baseline photograph of PRF group. (3B) Six months review photograph of PRF group. (3C) Baseline photograph of CTC group. (3D) Six months review photograph of CTG group.

uniform thickness of 1 to $1.5 \mathrm{~mm}$. The PRF was prepared in accordance with the protocol developed by Choukroun et al in 2000. ${ }^{17,19}$ PRF was then compressed into a membrane form. The matrices were inserted through the horizontal incision on the buccal side and passed over the crest of the interdental bone, such that the matrix extends onto the palatal interdental bone. A horizontal mattress suture was placed on the buccal and palatal aspect to stabilize the graft. A vertical mattress suture was placed on the interdental papilla and suspended on the composite resin placed adjacent to the coronal point of the contact area ( - Fig. 1D, 2D). The surgical site was covered with periodontal dressing.

After surgery, patients were prescribed with antibiotics and analgesics for 5 days. The periodontal dressing and the sutures were removed at the end of 2 weeks.

\section{Follow-Up}

Interdental PH, BTH, and site-specific PPD and CAL were reassessed at 6 months ( - Fig. 3). In addition, VAS scores for papillary gain and esthetics were given by dentists and patients respectively.

\section{Statistical Analysis}

The data were analyzed by SPSS (IBM SPSS statistics for Windows, version 22.0, NY: IBM corp. released 2013). The significance level was fixed as $5 \%(\alpha=0.05)$ and $(p \leq 0.05)$. The normality tests Kolmogorov-Smirnov and Shapiro Wilk test results revealed that except age, other variables did not follow normal distribution. To compare all the clinical parameters and outcome variables between CTG and PRF group, Mann Whitney U test was applied, and to compare the values between baseline and 6 months' time points within both the groups, Wilcoxon signed rank test was used. 


\section{Results}

The data were recorded for all the clinical parameters like PPD, CAL, FMPS, FMBS, interdental PH, BTH at baseline and at 6 months. Additionally, VAS scores were also collected at baseline and 6 months using photographs evaluated by patients as well as dentist.

The descriptive statistics for age, gender, and clinical parameters of patient recruited at baseline are represented in - Table 1. Data were represented as mean \pm standard deviation for age, PPD, CAL, PH, and BTH at the surgical site. Gender, FMPS. and FMBS were expressed as percentages. The results showed that these variables did not demonstrate statistically significant differences between the study groups. This indicates that at the time of recruitment, patients in the CTG and PRF groups showed no significant differences between them.

The clinical parameters such as FMPS, FMBS, PPD, and CAL did not show any statistical differences at any time points within the group and between the groups except CAL, which improved in CTG group at six months $(p=0.056)(-$ Table 2 ).

The comparison of primary and secondary outcome variables was done using Wilcoxon signed rank test between baseline and 6 months in the CTG group (-Table 3) and the PRF group ( - Table 4). There was a significant improvement in the primary outcome variables such as $\mathrm{PH}$ and BTH from baseline to 6 months $(p \leq 0.05)$. Similarly, a significant improvement was also observed in the secondary outcome variables VAS-D and VAS-P from baseline to six months $(p \leq 0.05)$.

Table 1 Descriptive statistics of all the clinical parameters between CTG and PRF group at baseline

\begin{tabular}{|c|c|c|c|c|c|}
\hline \multicolumn{2}{|c|}{ Parameters/Groups } & $\begin{array}{l}\text { CTG group } \\
(\text { mean } \pm S D)\end{array}$ & $\begin{array}{l}\text { PRF group } \\
\text { (mean } \pm S D \text { ) }\end{array}$ & Z-value & $\begin{array}{l}p \text {-Value } \\
(p \leq 0.05)\end{array}$ \\
\hline \multicolumn{2}{|c|}{ Age (years) } & $39.30 \pm 5.75$ & $37.10 \pm 8.79$ & 0.514 & 0.521 \\
\hline \multirow[t]{2}{*}{ Gender } & Male (\%) & $70 \%$ & $60 \%$ & \multirow[t]{2}{*}{0.269} & \multirow[t]{2}{*}{0.612} \\
\hline & Female (\%) & $30 \%$ & $40 \%$ & & \\
\hline \multicolumn{2}{|c|}{ PPD (mm) } & $1.46 \pm 0.55$ & $1.22 \pm 0.23$ & 0.266 & 0.607 \\
\hline \multicolumn{2}{|c|}{$\mathrm{CAL}(\mathrm{mm})$} & $1.14 \pm 0.63$ & $1.14 \pm 0.77$ & 0.152 & 0.788 \\
\hline \multicolumn{2}{|c|}{ FMPS (\%) } & $10.68 \pm 2.83$ & $11.60 \pm 4.41$ & 0.164 & 0.790 \\
\hline \multicolumn{2}{|c|}{ FMBS (\%) } & $11.16 \pm 2.73$ & $12.09 \pm 5.50$ & 0.201 & 0.879 \\
\hline \multicolumn{2}{|c|}{$\mathrm{PH}(\mathrm{mm})$} & $2.40 \pm 0.70$ & $2.40 \pm 0.97$ & 0.739 & 0.870 \\
\hline \multicolumn{2}{|c|}{ BTH (mm) } & $3.30 \pm 0.48$ & $3.40 \pm 1.17$ & 0.428 & 0.840 \\
\hline
\end{tabular}

Abbreviations: BTH, black triangle height; CAL, site-specific clinical attachment level; FMBS, full mouth bleeding scores; FMPS, full mouth plaque scores; $\mathrm{PH}$, interdental papillary height; PPD, site-specific probing pocket depth.

Table 2 Intragroup and intergroup comparison of site-specific PPD and CAL between baseline and six months in CTG and PRF group

\begin{tabular}{|l|l|l|l|}
\hline Variables & PRF & CTG & $p$-Value \\
\hline PPD-Baseline & $1.22 \pm 0.23$ & $1.46 \pm 0.55$ & 0.607 \\
\hline PPD-6 months & $1.44 \pm 0.22$ & $1.28 \pm 0.25$ & 0.135 \\
\hline$p$-Value & 0.102 & 0.444 & \\
\hline CAL-baseline & $1.14 \pm 0.74$ & $1.14 \pm 0.63$ & 0.788 \\
\hline CAL-6 months & $0.51 \pm 0.65$ & $0.62 \pm 0.66$ & 0.780 \\
\hline$p$-Value & 0.028 & 0.721 & \\
\hline
\end{tabular}

Abbreviations: CAL, site-specific clinical attachment level; PPD, site-specific probing pocket depth.

Table 3 Intragroup comparison of primary and secondary outcome variable between baseline and six months in CTG group

\begin{tabular}{|l|l|l|l|l|}
\hline Parameters/Time points & $\begin{array}{l}\text { Baseline } \\
\text { (mean } \pm \text { SD) }\end{array}$ & $\begin{array}{l}\text { Six months } \\
(\text { mean } \pm \text { SD) }\end{array}$ & Z-value & $\begin{array}{l}\boldsymbol{p} \text {-Value } \\
(\boldsymbol{p} \leq \mathbf{0 . 0 5})\end{array}$ \\
\hline Papillary height $(\mathrm{mm})$ & $2.40 \pm 0.70$ & $3.50 \pm 0.85$ & 2.598 & $\mathbf{0 . 0 0 9 ^ { * }}$ \\
\hline Black triangle height $(\mathrm{mm})$ & $3.30 \pm 0.48$ & $1.40 \pm 0.70$ & 2.913 & $\mathbf{0 . 0 0 4 ^ { * }}$ \\
\hline Visual analog score-dentist & $1.08 \pm 0.54$ & $7.54 \pm 1.28$ & 2.814 & $\mathbf{0 . 0 0 5}^{*}$ \\
\hline Visual analog score-patient & $3.00 \pm 0.94$ & $7.30 \pm 1.57$ & 2.721 & $\mathbf{0 . 0 0 7}^{*}$ \\
\hline
\end{tabular}

$*(p \leq 0.05)$ statistically significant. 
Table 4 Intragroup comparison of primary and secondary outcome variable between baseline and six months in PRF group

\begin{tabular}{|c|c|c|c|c|}
\hline Parameters/Time points & $\begin{array}{l}\text { Baseline } \\
\text { (mean } \pm \text { SD) }\end{array}$ & $\begin{array}{l}\text { Six Months } \\
\text { (mean } \pm S D \text { ) }\end{array}$ & Z-value & $\begin{array}{l}p \text {-Value } \\
(p \leq 0.05)\end{array}$ \\
\hline Papillary height (mm) & $2.40 \pm .97$ & $3.10 \pm 1.10$ & 2.646 & $0.008^{*}$ \\
\hline Black triangle height (mm) & $3.40 \pm 1.17$ & $2.50 \pm 1.08$ & 2.714 & $0.007^{*}$ \\
\hline Visual analog score-dentist & $0.93 \pm 0.62$ & $4.98 \pm 2.31$ & 2.807 & $0.005^{*}$ \\
\hline Visual analog score-patient & $3.00 \pm 1.76$ & $5.70 \pm 2.31$ & 2.714 & $0.007^{*}$ \\
\hline
\end{tabular}

$*(p \leq 0.05)$ statistically significant.

Table 5 Intergroup comparison of primary and secondary outcome variables at six months

\begin{tabular}{|l|l|l|l|l|}
\hline Parameter/group & $\begin{array}{l}\text { CTG group } \\
\text { (mean } \pm \text { SD) }\end{array}$ & $\begin{array}{l}\text { PRF group } \\
(\text { mean } \pm \text { SD) }\end{array}$ & $\begin{array}{l}\text { Z-value } \\
(\boldsymbol{p} \leq \mathbf{0 . 0 5})\end{array}$ & 0.376 \\
\hline Papillary height $(\mathrm{mm})$ & $3.50 \pm 0.85$ & $3.10 \pm 1.10$ & 0.885 & $\mathbf{0 . 0 1 8 ^ { * }}$ \\
\hline Black triangle height $(\mathrm{mm})$ & $1.40 \pm 0.70$ & $2.50 \pm 1.08$ & 2.368 & $\mathbf{0 . 0 1 0 ^ { * }}$ \\
\hline Visual analog score-dentist & $7.54 \pm 1.28$ & $4.98 \pm 2.31$ & 2.580 & 1.371 \\
\hline Visual analog score-patient & $7.30 \pm 1.57$ & $5.70 \pm 2.31$ & 0.171 \\
\hline
\end{tabular}

$*(p \leq 0.05)$ statistically significant.

- Table 5 shows the comparison of primary and secondary outcome variables between the CTG and PRF group at six months. The PH in the CTG group was comparable with that of the PRF group $(p=0.376)$. However, BTH was reduced significantly in the CTG group (1.40 \pm 0.70$)$ compared with the $\operatorname{PRF}$ group $(2.50 \pm 1.08)(p=0.018)$. The visual analogue score by dentist also shows significant difference, with the scores of CTG group (7.54 \pm 1.28$)$ better than those of the PRF group $(4.98 \pm 2.31)(p=0.010)$. VAS-P scores were similar in both the groups at 6 months $(p=0.171)$.

\section{Discussion}

Reconstruction of the lost interdental papillary tissues has persistently challenged the dentist because of its restricted vascularity and reduced regenerative potential. A multitude of surgical and nonsurgical procedures were proposed in the past few decades for effective regeneration of papilla.

When the surgical procedures were reviewed, the initial studies for papillary reconstruction were all based on flap-elevation procedures. ${ }^{20,21}$ Later on, considering the vascular architecture of interdental papilla and its healing potential, less invasive flapless tunneling procedures were preferred, which were carried out mostly on the buccal aspect alone. ${ }^{5-7}$ However, the importance of the matrix was not highlighted in these surgical techniques.

In the present study, a novel papillary augmentation access was proposed where both buccal and palatal tunneling was performed with the placement of CTG and $\mathrm{PRF}^{22-25}$ as matrices, and the papilla being displaced as a gingivopapillary unit.

All the primary and secondary outcome variables demonstrated a significant improvement within the group from baseline to six months. The $\mathrm{PH}$ was similar between the groups at six months without any significant differences. This is in accordance with multiple case reports and case series where $\mathrm{CTG}^{8,26}$ and PRF $\mathrm{P}^{11,12,14,27}$ favorably influenced the PH. The reduction of BTH was more significant in the CTG group than in the PRF group. Despite no difference in $\mathrm{PH}$, there was a significant reduction of BTH in 6 months. The possible reason could be that due to the tunneling of the papilla with adjacent gingiva and advancing it as a unit there was some amount of root coverage also happened along with the papillary fill, which is evidenced in the form of improvement in CAL in both CTG and PRF groups. This implies that papilla shifted coronally along with its base. Hence, there is no significant change in the papillary height, whereas when the whole unit was coronally advanced, BTH reduced significantly in both the groups.

Although PRF group shows a significant improvement in papillary height and reduction of BTH at 6 months, on comparison to CTG group, a considerably lower BTH reduction was observed. This could be attributed to the biological tissue characteristics of $\mathrm{CTG}^{28}$ that substantiate and suggest CTG as a better matrix for papilla augmentation..$^{29,30}$

The visual analogue scores by patient for esthetics were similar between the groups, whereas the visual analogue scores by dentist for papillary fill were significantly better in CTG group than in the PRF group. This has further favored the effectiveness of CTG for papillary fill.

The limitations of the present study were smaller sample size with shorter follow-up period of only 6 months. Further, radiographic bone crest to contact point distance was not considered as a selection criterion. A separate study group to assess the efficacy of the technique alone without addition of any biological matrices could have highlighted the benefits of the technique alone. Although the amount of PRF were reported to influence the treatment outcome, quantification of PRF was not done in the present study. ${ }^{31}$ 


\section{Conclusion}

Despite the limitations, the results of the present study revealed that a significant papillary gain and reduction of BTH was obtained in both CTG and PRF groups, with CTG showing significantly better effectiveness in reduction of BTH than PRF, when used as a biological matrix in the proposed papillary augmentation access.

\section{Conflict of Interest}

None declared.

\section{References}

1 Tarnow DP, Magner AW, Fletcher P. The effect of the distance from the contact point to the crest of bone on the presence or absence of the interproximal dental papilla. J Periodontol 1992;63(12):995-996

2 Al-Zarea BK, Sghaireen MG, Alomari WM. Bheran H, Taher I. Black triangles causes and management: a review of literature. Br J Appl Sci Technol 2015;6(1):1-7

3 Beagle JR. Surgical reconstruction of the interdental papilla: case report. Int J Periodontics Restorative Dent 1992;12(2):145-151

4 Han TJ, Takei HH. Progress in gingival papilla reconstruction. Periodontol 2000 1996;11:65-68

5 Azzi R, Etienne D, Carranza F. Surgical reconstruction of the interdental papilla. Int J Periodontics Restorative Dent 1998;18(5):466-473

6 Azzi R, Takei HH, Etienne D, Carranza FA. Root coverage and papilla reconstruction using autogenous osseous and connective tissue grafts. Int J Periodontics Restorative Dent 2001;21(2):141-147

7 Carnio J. Surgical reconstruction of interdental papilla using an interposed subepithelial connective tissue graft: a case report. Int J Periodontics Restorative Dent 2004;24(1):31-37

8 Nemcovsky CE. Interproximal papilla augmentation procedure: a novel surgical approach and clinical evaluation of 10 consecutive procedures. Int J Periodontics Restorative Dent 2001;21(6):553-559

9 Lambodharan R, Balaji VR. Interdental papilla regeneration around implants: A novel window technique (2 years follow-up) J Pharm Bioallied Sci 2015;7(Suppl 2):S815-S818

10 Choukroun J, Diss A, Simonpieri A, et al. Platelet-rich fibrin (PRF): a second-generation platelet concentrate. Part V: histologic evaluations of PRF effects on bone allograft maturation in sinus lift. Oral Surg Oral Med Oral Pathol Oral Radiol Endod 2006;101(3):299-303

11 Muthukumar S, Rangarao S. Surgical augmentation of interdental papilla - A case series. Contemp Clin Dent 2015;6(Suppl 1):S294-S298

12 Arunachalam LT, Merugu S, Sudhakar U. A novel surgical procedure for papilla reconstruction using platelet rich fibrin. Contemp Clin Dent 2012;3(4):467-470

13 Mathur A, Bains VK, Gupta V, Jhingran R, Singh GP. Evaluation of intrabony defects treated with platelet-rich fibrin or autogenous bone graft: A comparative analysis. Eur J Dent 2015;9(1):100-108

14 Rattanasuwan K, Rassameemasmaung S, Kiattavorncharoen S, Sirikulsathean A, Thorsuwan J, Wongsankakorn W. Platelet-rich plasma stimulated proliferation, migration, and attachment of cultured periodontal ligament cells. Eur J Dent 2018;12(4):469-474

15 Shruthi S, Gujjari SK, Mallya KP. Comparison of two surgical techniques for the reconstruction of interdental papilla. J Interdiscip Dentistry. 2015;5(1):17-22

16 Chaulkar PP, Mali RS, Mali AM, Lele PA, Patil PA. A comparative evaluation of papillary reconstruction by modified Beagle's technique with the Beagle's surgical technique: A clinical and radiographic study. J Indian Soc Periodontol 2017;21(3):218-223

17 O'Leary TJ, Drake RB, Crump PP, Allen MF. The incidence of recession in young males: a further study. J Periodontol 1971;42(5):264-267

18 Ainamo J, Bay I. Problems and proposals for recording gingivitis and plaque. Int Dent J 1975;25(4):229-235

19 Toffler M, Toscano N, Holtzclaw D, Corso MD, Ehrenfest DD. Introducing Choukroun's platelet rich fibrin (PRF) to the reconstructive surgery milieu. J Implant Adv Clin Dent. 2009;1(6):21-30

20 Cortellini P, Prato GP, Tonetti MS. The modified papilla preservation technique. A new surgical approach for interproximal regenerative procedures. J Periodontol 1995;66(4):261-266

21 Becker W, Gabitov I, Stepanov M, Kois J, Smidt A, Becker BE. Minimally invasive treatment for papillae deficiencies in the esthetic zone: a pilot study. Clin Implant Dent Relat Res 2010;12(1):1-8

22 Agarwal SK, Jhingran R, Bains VK, Srivastava R, Madan R, Rizvi I. Patient-centered evaluation of microsurgical management of gingival recession using coronally advanced flap with platelet-rich fibrin or amnion membrane: A comparative analysis. Eur J Dent 2016;10(1):121-133

23 Sharma A, Aggarwal N, Rastogi S, Choudhury R, Tripathi S. Effectiveness of platelet-rich fibrin in the management of pain and delayed wound healing associated with established alveolar osteitis (dry socket) Eur J Dent 2017;11(4):508-513

24 Samani MK, Saberi BV, Ali Tabatabaei SM, Moghadam MG. The clinical evaluation of platelet-rich plasma on free gingival graft's donor site wound healing. Eur J Dent 2017;11(4):447-454

25 Tavassoli-Hojjati S, Sattari M, Ghasemi T. Ahmadi R, Mashayekhi A. Effect of platelet-rich plasma concentrations on the proliferation of periodontal cells: An in vitro study. Eur J Dent 2016;10(4):469-474

26 Kaushik A, Pk P, Jhamb K, et al. Clinical evaluation of papilla reconstruction using subepithelial connective tissue graft. J Clin Diagn Res 2014;8(9):ZC77-ZC81

27 Ahila E, Saravana Kumar R, Reddy VK, Pratebha B, Jananni M, Priyadharshini V. Augmentation of interdental papilla with platelet-rich fibrin. Contemp Clin Dent 2018;9(2):213-217

28 Csiszar A, Wiebe C, Larjava H, Häkkinen L. Distinctive molecular composition of human gingival interdental papilla. J Periodontol 2007;78(2):304-314

29 Plato Palathingal JM. Treatment of black triangle by using a sub-epithelial connective tissue graft. J Clin Diagn Res 2011;5(8):1688-1691

30 Sharma A, Singal V. Connective tissue: A gold standard for reconstruction of black triangle. J Curr Res Sci Med. 2017;3(2):111-114

31 Culhaoglu R, Taner L, Guler B. Evaluation of the effect of dose-dependent platelet-rich fibrin membrane on treatment of gingival recession: a randomized, controlled clinical trial. J Appl Oral Sci 2018;26:e20170278 